\title{
Y.I. AL MASHHADANY \\ DESIGN AND ANALYSIS OF 7-DOF HUMAN-LINK MANIPULATOR BASED ON HYBRID INTELLIGENT CONTROLLER
}

\section{Al Mashhadany Y.I. Design and Analysis of 7-DOF Human-Link Manipulator Based on Hybrid Intelligent Controller.}

Abstract. A manipulator is an alternative to progress profitability in mechanical computerization. The robotic controller executes forms' assembly operations in hazardous conditions. Since computerized controllers are highly vulnerable nonlinear powerful frameworks, it is hard to provide precise unique conditions at controlling laws' configuration. Virtual Reality (VR) is a fundamental advance at use in modern biomedical, medical procedures and different fields where a 3D object helps to comprehend complex behavior. This work proposes the interaction with 3D models in VR environment achieved by accurate sensing from feedback, and then reconstructs the instruction according to practical limitation of a real human arm movement.

In this work ANFIS played a key role in finding results with optimal values because the combination of Neural Networks (NN) benefits and obscure logic systems research examined the individual defects in both of them. Use of Artificial Neural Networks (ANN) in dynamic systems has quite extensive and accurate results, when adding a training signal system to the mixed learning base implemented at combining the slope proportions technique, a Least Square Error (LSE) preparing the ANFIS organization for any framework to take care of the issue any way. This work presents a keen controller actualization with 7-DOF controller for a model designed with a VR situation that reproduces the system design by associating Matlab/Simulink to connect the VR model with some instruction to execute orders delivered by the hybrid intelligent controller based on ANFIS technique. Palatable outcomes are implemented in reproductions that improve the procedure as an essential utilization of this controller design.

Keywords: Human-Link Manipulator, Hybrid Intelligent Controller, Virtual Reality, Artificial Neural Networks.

1. Introduction. Since the beginning of this century, working with neural networks (NNs) has become effective in numerous troublesome mechanical applications. However, handy encounters have demonstrated that each of these two astute innovations has its constraints in working with their own application deserts that point to restriction of their valuable usage in certain frameworks, particularly the intricate ones $[1,2]$. So, to find an answer to this logical issue, a few tests were run to incorporate FL and ANN into a bound together framework that prompted the rise of a fast and precise improvement in the craft by puzzling synapses. Today ANFIS has become one of the most generally utilized neural frameworks and has been proposed by numerous classifiers $[3,4]$.

Fuzzy system has form information achieved by means of fractional set participation instead of a fresh one. Like neural system FL can create 
unmistakable results from obscure vague uncertain and missing input data. An appropriate FIS is basic to rectify fuzzy enrollment capacities and fuzzy standards. Yet building it requires some investment and necessities, as well as special skills. Another problem is to change space information from a poor out-of-business opportunity, even for industry professionals [5-7].

In the mid-1990s an intelligent system called ANFIS was created. Adhering to ideas that the rationale is fuzzy and nervous; it is a framework across a granular strain that improves learning and programmed adaptation. Specialists have used such a framework to anticipate and display different construction frameworks. One of the basics in versatile neural learning strategies is a thin display technique that learns the informational index and natural registers /registration work parameters/ that allow to get the best possible degree for FIS by following information / yield information [8-10].

The recording work parameters are set by a mixture of least square estimation and back reproductive calculation in order to estimate the sharing work parameter. Parameters change through an educational procedure as it is in the nervous system. Their changing is encouraged by an angle vector, which determines what information the FIS models have for specific arrangements of parameters. When the angle vector is received, any of a few advancement schedules can change the parameters to lessen the mistake between the genuine and the ideal yields. The fluffy framework at that point gains from the information demonstrating. The change of the participated work limits does not have to deal with a human administrator, so, this is a preferred position over unadulterated fluffy worldview [11-13].

Nonstop and boring assignments of lines creation are tiring, and weakness can cause some damage in medical issues. A robot controller arm can more than once convey immense and substantial parts starting with one generated line onto the next one, so, these days it is widely utilized at processing plants to build effectiveness and handle rehashed/risky/sensitive undertakings (e.g., semiconductor wafer creation) [14-16].

Opposite kinematics is one of the fundamental issues in mechanical autonomy, and it is frequently handled at differential level since joint space speed maps straight to Cartesian space speed. Subsequently registering the joint space speed from a given Cartesian end-effector speed can be viewed as a straight relapse issue. Thus, it is notable that the Jacobian lattice of the controller, speaking about this direct mapping, can be ranked insufficient (should there be an occurrence of kinematic singularities) and regardless of whether its full-position has a larger number of segments than columns (in the event of repetitive controllers), hence the straight relapse is not a well presented issue $[17,18]$. 
The plan of contrasting the most common arrangements with the kinematic singularities issue depends on regularization drawing near for the most part known as damped least squares arrangements, which are used in the regularization technique by Tikhonov (1963) working with poorly presented direct relapse issues. The thought is to explain a poorly presented direct reversal issue by presenting it in the cost work, together with the remaining of the relapse, a punishing term for the standard of the arrangement. The most basic issue in such methodologies is the determination of the weight, the alleged damping factor, of such an extra term [19]. An extraordinary ANFIS learning methodology, called invert (TBP), was used to control non-direct MIMO systems by trading between units suitable to each time sample [20]. In any case, this strategy is portrayed by serious estimation and advancement in execution [21].

Another preparation model with ANFIS as intelligent controller with nonlinear and complex MIMO design is a reverse training; the ANFIS arrangements are prepared to get familiar with the opposite elements of the system it controls. Its prosperity, nonetheless, is significant with three components like: exact displaying of the first framework (an issue when the framework is perplexing), accessibility of the framework backward elements (generally they do not exist), and fitting dissemination of the prepared information (could be inconceivable, given imperatives of the framework elements) $[22,23]$. There exists another preparation approach different from the previously referenced ones.

Present robot route frameworks request controllers that can consider certain complex issues in dubious and dynamic situations. ANFIS gathers intrigue since this provides the advantages of combining NN and FL, and evacuates their separate burdens by consolidating them with their basic highlights. ANN is the other inspiration to be examined into FL. It may be successfully utilized as a widespread learning worldview by including fluffy derivation frameworks $[24,25]$.

Conventional robot control techniques depend on solid scientific displaying, examination and amalgamation. Existing methodologies are suitable to the controllers of portable robots operating under obscure conditions and running errands that require development in unique situations. Operational assignments under the unstructured conditions, for instance, on distant planets or at dangerous waste locales, that are progressively intricate, the explanatory demonstrating is deficient yet. $\mathrm{Nu}$ merous scientists and architects have attempted to somehow resolve the navigational issues of versatile robot frameworks [26, 27].

Despite the fact that fuzzy frameworks can utilize information based on semantic principles (and hence could actualize master human 
information and experience), fuzzy controller has no efficient structure strategy. Tuning of participated work parameters requires some investment. NN training procedures can robotize the procedure with advancement and execution improved [28, 29].

The actualization of ANN with FL system has conveyed neurofuzzy as dynamic smart control and made their current unmistakable quality. Continuing free interstate any robot should have a choice to perceive its condition, between recognized data and information received on its circumstance and condition, plan a course which brings it to the objective circumstance from a concealed position, with square staying away and controlling its heading and speed. $\mathrm{Ng}$ et al. [30] present a neuraljoined warm controller that heads FL delineation of human information with NN understanding how to deal with nonlinear wonderful control issues. Pham et al. concentrate on making sharp multi-head robot bunches fit for both independent movement and dynamic-condition joint exertion at achieving bunch objectives [31, 32].

The additional propose of the neuro-fuzzy adaptable development chooses a structure that empowers robot experts get-together to accomplish versatile wonderful control of steady assignment [33]. Portraying selfmanaging course in versatile robots as an intrigue methodology inside a course situation, that contains squares and targets, proposes a padded NN controller, that contemplates course heading and course speed as controllable. Rutkowski et al. [34] understood an adaptable neuro-fuzzy social event of a framework; their method gathers basic and plan adaptability in neurofuzzy structures. Hui et al. also, Rusu et al. took a gander at neurocomfortable controllers of sensor-based versatile robot course. Garbi et al. executed an adaptable neuro-padded acknowledgment structure in a mechanical vehicle course $[35,36]$.

Manipulators are one approach to manage progress in mechanical mechanization gainfullness. Automated controllers have been utilized in making operations under standard and hazardous conditions. They are altogether nonlinear unfathomable frameworks which tend to vulnerabilities. Attaining the exact unfathomable conditions for their control laws is dangerous. Vulnerabilities with the dynamic models combine cloud payloads and obscure frictional coefficients. Universal control or no model vigilant control was strongly recommended as being able to compensate for these vulnerabilities [37].

The enhanced simulation framework is a visual case of the PC interface, which can be linked to a dynamic frame model to clearly reflect the direction and condition of the framework [38]. Virtual model was developed to utilize genuine robot design. Simulink 3D Animation is sort of a 
characteristic program giving Simulink Models an inconceivable association, the language of the above program is Virtual Reality Modeling Language (VRML). Brief delineation of making the virtual structure: the mechanical arm is tied as an individual component, the article contains a change hub, a design hub and a shape pivot, in the building hub; the robot arm geometry is set while in the shape hub; the appearance and concealing are picked. The change center contains the article organization, focus point, interpretation, and pivot field rules; these characteristics are related to the body sensor in Sim-Mechanics model connections in which the element arrangement is made by facilitating the activation of the robot arm wrapping, and it is activated by the dynamic frame movement verified in a constant. The state of the connections and the revolution of the robot joints are given in the designed Simulink form [39].

The usage of physical frameworks in a pragmatic manner is viewed as intricate, so working with VR innovation was an essential answer to some issues in building frameworks, therapeutic applications and different fields, that rely upon working in $3 \mathrm{D}$, since it helps to understand complex frameworks. In numerous applications the connections with virtual frameworks can be augmented by a tactile sense, and fast notes can be utilized to apply agent forces of VR condition to a human client [40]. Stem responses are additionally helpful in tele-medical procedure, where the fundamental specialist carefully guides specialized sensitive instruments and in a result receives sensible responses. While numerous frameworks that give compensatory criticism have been created, many issues came under the class of cutting edge explore models, which have turned out to be based on vitality input as they gave third outcomes to these intricate frameworks [41].

Direction in position, velocity and an increased velocity in focus were compared over time. The above was developed for the centers that allow the robot to move in multidimensional Cartesian space. The life of Cartesian pattern is accomplished for three conditions of the street. Cases are given as the immediate development technique and a bended strategy with a different point strategy. Case 1 and 2 are the techniques for straight movement by doing synchronous interpretation. Case 3 is a bended technique with a polynomial capacitance that is highly isolated by focus points. The joint's direction (point, speed, and increasing speed) in a common area is determined by applying retrograde kinematics to the robot [42].

The developing control of human controllers is the primary component in dynamic examination, and the most significant hindrance to be defeated is the issue of the front and back motor on the grounds that the 
7-DOF invert kinematic movements have numerous arrangements which prompt stereoscopic arrangements. In this field there is no complete clarification and exact answer about such structures, control [43] and dodging obstructions for human controllers. For sequential processors, the switch drive is substantially more troublesome than the front drive. By and large, the dynamic development can be switched in a few different ways to arrive at a numerical, investigative and geometric technique. The numerical strategy is utilized [43], yet investigative strategies can arrive at all potential arrangements extensively and precisely. There is an incredible trouble in extricating potential arrangements yet utilizing techniques are straightforward building, however it is reasonable for several sorts of controllers [44]. This work introduces the structure of the ANFIS support to the processor model, that was worked out based on the computer- generated experience and condition, and reproduces the model with associating Matlab 2019b/Simulink and VR for executing directions created by its framework based on the ANFIS comfort. A contextual analysis, which recreated 7-DOF human controller, fulfilled outcomes received at reproductions, and improved the structure as a fundamental use of this control framework; prologue to the methodology in the primary area. The subsequent area displays the active model of 7-DOF human controller, then shows the ANFIS controller design and training strategies for intelligent control. Area $\mathrm{V}$ delineates the genuine model for human manipulator arm taking care of Segment IV that shows a mimicked contextual analysis of framework structure up to the end.

2. Kinematics Solution for 7-DOF Human Manipulator. The situation of controller joints is determined based on the estimations of the joint points utilized by the front engines [37, 38]. This technique is viewed as one of the most exact strategies in the field of work inspecting and delivering frameworks of converse elements. At the point, when the arm scope of activity is to be determined by considering a shoulder width denoted as $\mathrm{D}$ parameter, with its upper safe distance $\mathrm{L}_{1}$, and a length of the lower end $\mathrm{L}_{2}$ considered, the shoulder area $\left(\mathrm{PP}_{1}\left(0,-\mathrm{D}_{\mathrm{T}}, 0\right)\right)$, and a situation for elbow is $\left(\mathrm{PP}_{2}\left(x_{p p 2}, y_{p p 2}, z_{p p 2}\right)\right.$. The joint is named $\left(\mathrm{qq}_{1} \ldots \mathrm{qq}_{7}\right)$ and in the event that the expected situation of the essential joint is I in connection to I-1 with a homogeneous network $4 \times 4{ }^{\mathrm{i}-1} \mathrm{~T}_{\mathrm{i}}$ as derived from equation (1).

Assuming that the situation of the seventh joint in the fixed arrange $\left(\mathrm{PP}_{3}\left(x_{p p 3}, y_{p p 3}, z_{p p 3}\right)\right.$, given that its points are spoken to by (R-P$\mathrm{Y}$ (Roll-Pitch-Yaw) is $\psi$. Under these directions, the seventh position can be depicted by a homogeneous lattice ${ }^{0} \mathrm{~T}_{7}$ : 


$$
\begin{aligned}
& { }^{0} T_{1}=\left[\begin{array}{cccc}
c q q_{1} & 0 & s q q_{1} & 0 \\
0 & 1 & 0 & -D_{T} \\
-s q q_{1} & 0 & c q q_{1} & 0 \\
0 & 0 & 0 & 1
\end{array}\right],{ }^{1} T_{2}=\left[\begin{array}{cccc}
1 & 0 & 0 & 0 \\
0 & c q q_{2} & -s q q_{2} & 0 \\
0 & s q q_{2} & c q q_{2} & 0 \\
0 & 0 & 0 & 1
\end{array}\right], \\
& { }^{2} T_{3}=\left[\begin{array}{cccc}
c q q_{3} & -s q q_{3} & 0 & 0 \\
s q q_{3} & c q q_{3} & 0 & 0 \\
0 & 0 & 1 & 0 \\
0 & 0 & 0 & 1
\end{array}\right],{ }^{3} T_{4}=\left[\begin{array}{cccc}
1 & 0 & 0 & 0 \\
0 & c q q_{4} & -s q q_{4} & 0 \\
0 & s q q_{4} & c q q_{4} & 0 \\
0 & 0 & 0 & 1
\end{array}\right], \\
& { }^{4} T_{5}=\left[\begin{array}{cccc}
c q q_{5} & -s q q_{5} & 0 & 0 \\
s q q_{5} & c q q_{5} & 0 & 0 \\
0 & 0 & 1 & 0 \\
0 & 0 & 0 & 1
\end{array}\right], \quad{ }^{5} T_{6}=\left[\begin{array}{cccc}
1 & 0 & 0 & 0 \\
0 & c q q_{6} & -s q q_{6} & 0 \\
0 & s q q_{6} & c q q_{6} & 0 \\
0 & 0 & 0 & 1
\end{array}\right], ; \\
& { }^{6} T_{7}=\left[\begin{array}{cccc}
c q q_{7} & 0 & s q q_{7} & 0 \\
0 & 1 & 0 & -D_{T} \\
-s q q_{7} & 0 & c q q_{7} & 0 \\
0 & 0 & 0 & 1
\end{array}\right]
\end{aligned}
$$

the symbols: $\mathrm{sqq}_{\mathrm{i}}=\sin \left(\mathrm{qq}_{\mathrm{i}}\right) ; \mathrm{cqq}_{\mathrm{i}}=\cos \left(\mathrm{qq}_{\mathrm{i}}\right)$

$$
{ }^{0} T_{7}=\left[\begin{array}{cccc}
c \varphi c \theta & c \varphi s \theta s \psi-s \varphi c \psi & c \varphi s \theta c \psi+s \varphi s \psi & x_{p p 3} \\
s \varphi c \theta & s \varphi s \theta s \psi+c \varphi c \psi & s \varphi s \theta c \psi-c \varphi s \psi & y_{p p 3} \\
-s \theta & c \theta s \psi & c \theta c \psi & z_{p p 3} \\
0 & 0 & 0 & 1
\end{array}\right]
$$

The final posture of the racket can be calculated by matrix ${ }^{0} T_{7}$ as follows:

$$
{ }^{0} T_{7}={ }^{0} T_{1}^{1} T_{2}^{2} T_{3}^{3} T_{4}^{4} T_{5}^{5} T_{6}^{6} T_{7}\left[\begin{array}{cccc}
n_{x} & o_{x} & a_{x} & p p_{x} \\
n_{y} & o_{y} & a_{y} & p p_{y} \\
n_{z} & o_{z} & a_{z} & p p_{z} \\
0 & 0 & 0 & 1
\end{array}\right] .
$$

From the final angles $(\theta, \psi, \phi)$ can be calculated the final posture of the racket by equations (1) and (2) as follows: 


$$
\left\{\begin{array}{l}
\varphi=a \tan 2\left(n_{y}, n_{x}\right) \\
\theta=a \tan 2\left(-n_{z}, c \varphi n_{x}+s \varphi n_{y}\right) \\
\psi=a \tan 2\left(s \varphi a_{x}-c \varphi a_{y},-s \varphi o_{x}+c \varphi o_{y}\right) \\
x_{p p 3}=p p_{x} \\
y_{p p 3}=p p_{y} \\
z_{p p 3}=p p_{z}
\end{array}\right\} .
$$

Where $a \tan 2(\theta, \psi, \phi)$ is a quadratic invert shadow capacity, (3) a forward engine for the processor [18]. The Jacobian framework used to ascertain the speed from the hub region as per the speed of the working. The task connection for all system can be expressed mathematically as:

$$
V_{r}=J_{r}(q) \dot{q}
$$

The parameter $\boldsymbol{V}_{\boldsymbol{r}}$ represents the racket speed, while $\dot{q}$ represents the joint of space speed. The calculation of matrix (Jacobian matrix ) $\boldsymbol{J}$ with dimension $(6 \times 7)$, through differential transformation method with $i^{\text {th }}$ parameters of $\boldsymbol{J}_{\boldsymbol{r}}$ can be received:

$$
J_{i}=\left[\begin{array}{l}
\left(p p_{i} \times n_{i}\right)_{k} \\
\left(p p_{i} \times o_{i}\right)_{k} \\
\left(p p_{i} \times o_{i}\right)_{k} \\
n_{i k} \\
o_{i k} \\
a_{i k}
\end{array}\right]
$$

The parameters $\boldsymbol{a}_{\boldsymbol{i}}\left(a_{i x}, a_{i y}, a_{i z}\right), \boldsymbol{p} \boldsymbol{p}_{\boldsymbol{i}}\left(p p_{i x}, p p_{i y}, p p_{i z}\right), \boldsymbol{o}_{\boldsymbol{i}}\left(o_{i x}, o_{i y}, o_{i z}\right)$, and $\boldsymbol{n}_{i}\left(n_{i x}, n_{i y}, n_{i z}\right)$ represent the elements of matrix ${ }^{i-1} T_{i}$ :

$$
{ }^{i-1} T_{7}={ }^{i-1} T_{i} \ldots \ldots . .{ }^{6} T_{7}=\left[\begin{array}{cccc}
n_{x} & o_{x} & a_{x} & p p_{x} \\
n_{y} & o_{y} & a_{y} & p p_{y} \\
n_{z} & o_{z} & a_{z} & p p_{z} \\
0 & 0 & 0 & 1
\end{array}\right]
$$


The rotation of joint I is represented by symbol kk. For example, when the joint moved around $\mathrm{x}$-axis by $\mathrm{kk}$, the speed $\mathrm{Vr}$ with Jacobin $\mathrm{Jr}$ can be described by the Moore-Penrose (M. P) formula as follows:

$$
\dot{q}=J_{r}^{+} V_{r}
$$

Where $J_{r}^{+}=\left(J_{r}{ }^{T} J_{r}\right)^{-1} J_{r}{ }^{T}$ is the M.P pseudo reverse grid of $\boldsymbol{J}_{r}$. The position of an elbow $\mathrm{PP}_{2}$ is within circle at the axis and is $\mathrm{PP}_{1} \mathrm{PP}_{3}$. The position of the inside point and the areas of $\mathrm{PP}_{1}$ and $\mathrm{PP}_{3}$ decide the sweep (r) and the parameters for the length of arms $\mathrm{L}_{1}$ and $\mathrm{L}_{2}$, demonstrating the level developed with focuses $\mathrm{PP}_{1}, \mathrm{PP}_{2}$ and $\mathrm{PP}_{3}$ as $\Omega_{1}$, and the level built by focuses $\mathrm{O}, \mathrm{PP}_{1}$ and $\mathrm{PP}_{2}$ is as $\Omega_{2}$, showing the detachment edge somewhere in the

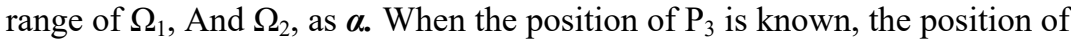
the $\mathrm{PP}_{2}$ elbow can be interestingly controlled by $\alpha$. On the off chance that focuses $\mathrm{O}, \mathrm{PP}_{1}$, and $\mathrm{PP}_{3}$ have a direct relationship while $\mathrm{PP}_{1}, \mathrm{PP}_{2}$, and $\mathrm{PP}_{3}$ do not exist, the $\Omega_{2}$, level does not exist. The point can be characterized as the detachment edge among $\Omega_{1}$, and the even plane. Additionally, if the $\mathrm{PP}_{1}$, $\mathrm{PP}_{2}$, and $\mathrm{PP}_{3}$ focuses are settled, the "1" level not available and the $\mathrm{PP}_{2}$ will be determined by the $\mathrm{PP}_{1}$ and $\mathrm{PP}_{3}$ positions and the $\mathrm{L}_{1}$ and $\mathrm{L}_{2}$ are safe distance variables. Given the general arrangement of a processor, as shown by Figure 1, the reversible of inverse components can be settled, if point $\alpha$ with the spots of its racket is given. As shown by the specifications of the improvement of human weapons, a mapping association between $\alpha$ and the position which can be worked and overcome of all an internal affiliation. The unit vector showing $\mathrm{PP}_{3}$ is insinuated as $\mathrm{PP}_{1}$ in the structure $\mathrm{I}\left(\mathrm{i}_{1}, \mathrm{i}_{2}, \mathrm{i}_{3}\right)$ and acknowledges that point $\alpha$ is enlisted by the decidedly ready ANN structure, by then the network can be modulated as follows:

$$
\left\{\begin{array}{c}
i_{1}\left(x x-x_{o}\right)+i_{2}\left(y y-y_{o}\right)+i_{3}\left(z z-z_{o}\right)=0 \\
\left(x x-x_{o}\right)^{2}+\left(y y-y_{o}\right)^{2}+\left(z z-z_{o}\right)^{2}=r^{2}
\end{array}\right\} .
$$

The available structure $\Omega_{2}$ and its hover meet at two focuses. One of the focuses close to the neck by $\mathrm{PP}_{\mathrm{w}}\left(\mathrm{xx}_{\mathrm{w}}, \mathrm{yy}_{\mathrm{w}}, \mathrm{zz}_{\mathrm{w}}\right)$ and point $\angle \mathrm{PP}_{2} \mathrm{O}^{\prime} ; \mathrm{PP}_{\mathrm{w}}$ is only a partition edge $\alpha$ somewhere in the range of $\Omega_{1}$ and $\Omega_{2}$. Indicate the standard vector of $\Omega_{2}$ as $n$ and the situation of $\mathrm{P}_{\mathrm{w}}$ ought to fulfill the condition [39]:

$$
\overrightarrow{O P P_{w}} \cdot n=0
$$




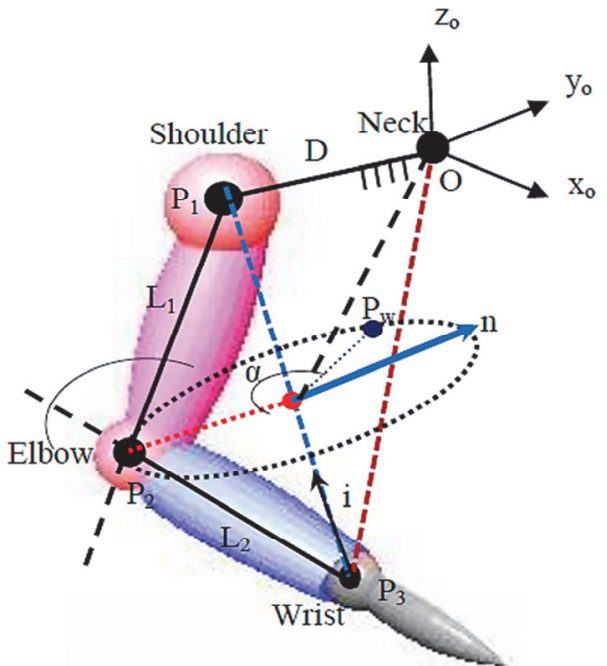

Fig. 1. 7-DOF human manipulator configuration

The position for $\mathrm{P}_{\mathrm{w}}$ can be determined by (8) and (10). Additionally, the position for $\mathrm{P}_{2}\left(\mathrm{x}_{\mathrm{p} 2}, \mathrm{y}_{\mathrm{p} 2}, \mathrm{z}_{\mathrm{p} 2}\right)$ meets the condition:

$$
\sqrt{\left(x_{p p 2}-x_{m}\right)^{2}+\left(y_{p p 2}-y_{m}\right)^{2}+\left(z_{p p 2}-z_{m}\right)^{2}}=2 r \sin \frac{\alpha}{2} .
$$

Position of $\mathrm{P}_{2}$ can be determined by (8) and (11). As indicated by the places of $\mathrm{P}_{1}, \mathrm{P}_{2}, \mathrm{P}_{3}$ and a cosine hypothesis, the point of joint 4 can be determined as:

$$
q_{4}=\pi-\cos ^{-1}\left(\frac{L_{1}^{2}+L_{2}^{2}-\left\|\overline{P P_{1} P P_{3}}\right\|^{2}}{2 L_{1} L_{2}}\right) .
$$

By using the position of $\mathrm{P}_{2}$, can be calculated the:

$$
\begin{aligned}
& {\left[\begin{array}{llll}
x_{p p 2} & y_{p p 2} & z_{p p 2} & 1
\end{array}\right]^{T}=} \\
& { }^{0} T_{1}{ }_{1} T_{2}{ }^{2} T_{3}\left[\begin{array}{cccc}
0 & 0 & -L_{1} & 1
\end{array}\right]^{T}
\end{aligned}
$$

At that point the edges of joint 1 and joint 2 can be determined as: 


$$
\left.\begin{array}{l}
q_{1}=a \tan 2\left(\frac{-x_{p 2}}{c q_{2} L_{1}}, \frac{-z_{p 2}}{c q_{2} L_{1}}\right)+k \pi ;(k \in N) \\
q_{2}=a \sin \left(\left(y_{p 2}+D\right) / L_{1}\right)
\end{array}\right\} .
$$

Also, by using the target position of $\mathrm{P}_{3}$, can be calculated the:

$$
\begin{gathered}
{\left[\begin{array}{cccc}
x_{p p 3} & y_{p p 3} & z_{p p 3} & 1
\end{array}\right]^{T}=} \\
={ }^{0} T_{1}^{1} T_{2}^{2} T_{3}^{3} T_{4}\left[\begin{array}{llll}
0 & 0 & -L_{2} & 1
\end{array}\right]^{T} .
\end{gathered}
$$

At that point the edge of joint 3 will be determined by:

$$
\left\{\begin{array}{l}
q_{3}=a \tan 2\left(\frac{y_{3}+D_{T}-s q_{2} L_{1}-s q_{2} c q_{4} L_{2}}{c q_{1} c q_{2} s q_{4} L_{2}} s q_{1} s q_{2}\right. \\
-\frac{x_{3}+s q_{1} c q_{2}\left(1+c q_{4}\right) L_{1}}{s q_{2} c q_{1} L_{1}}+ \\
\left.\frac{y_{3}+D_{T}-s q_{2} L_{1}}{c q_{2} s q_{4} L_{2}}-\frac{s q_{2} c q_{4}}{c q_{2} s q_{4}}\right)
\end{array}\right\}
$$

According to (2), at that point the edges of joints 5, 6, and 7 will be determined as:

$$
\left.\begin{array}{rl} 
& T_{5}^{4} T_{6}^{5} T_{7}^{6}=\left[T_{1}^{0} T_{2}^{1} T_{3}^{2} T_{4}^{3}\right]^{-1} T_{7}^{6}=T^{*} . \\
q_{5}= & a \tan 2\left(-T_{13}^{*}, T_{23}^{*}\right)+k \pi \quad(k \in N) \\
q_{6}= & a \tan 2\left(s q_{5} T_{13}^{*}-s q_{5} T_{23}^{*}, T_{33}^{*}\right) \\
q_{7}= & a \tan 2\left(-c q_{5} T_{12}^{*}-s q_{5} T_{22}^{*}, c q_{5} T_{11}^{*}+s q_{5} T_{21}^{*}\right)
\end{array}\right\} .
$$

Where: $T_{i j}^{*}$ is th $i^{t h}$ and $j^{i j}$ are matrix dimension of $T$.

3. ANFIS Controller Model. ANFIS is a system composed of ANN and FIS. At the first implement Takagi Sugeno (T.S.) assessed it as an intelligent system [40]. In the present investigation, four information sources are used: the front check separation $\left(\mathrm{x}_{1}\right)$, the correct impediment separation $\left(\mathrm{x}_{2}\right)$, the left snag separation $\left(\mathrm{x}_{3}\right)$ and the objective edge $\left(\mathrm{x}_{4}\right)$ and the yield is the guiding edge. On the off chance the rules for implementing the ANFIS structure, shown in Figure 2, are determined as follows: 
Rule: IF $x x_{1}$ is $A_{j}$;

$x x_{2} \quad$ is $B_{k} ; \quad x x_{3}$ is $C_{m}$ and $x_{4}$ is $\left.D_{n}\right\}$,

THEN $F_{i}=p p_{i} x x_{1}+r_{i} x x_{2}+s_{i} x x_{3}+t_{i} x x_{4}$

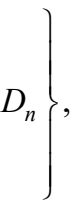

where

$$
\left.\begin{array}{l}
F_{i}=p p_{i} x x_{1}+r_{i} x x_{2}+s_{i} x x_{3}+t_{i} x x_{4}+u_{i} \\
\text { streeing angle: } \\
J J=1 \text { to } q_{1} ; \quad k k=1 \text { to } q_{2} ; \\
m m=1 \text { to } q_{3} ; \quad n n=1 \text { to } q_{4} ; \\
\text { and } i=1 \text { to } q_{1} \cdot q_{2} \quad q_{3} \cdot q_{4}
\end{array}\right\}
$$

$$
\left.\begin{array}{ccc}
L L_{2 g}=U_{a g}(x) & \text { for } & g g=1, \ldots . ., q_{1} \\
L L_{2 g}=U_{B g}(x) & \text { for } & g g=q_{1}+1, \ldots ., q_{1}+q_{2} \\
L L_{2 g}=U_{C g}(x) & \text { for } & g g=q_{1}+q_{2}+1, \ldots ., q_{1}+q_{2}+q_{3} \\
L L_{2 g}=U_{D g}(x) & \text { for } & g g=q_{1}+q_{2}+q_{3}+1, \ldots . ., q_{1}+q_{2}+q_{3}+q_{4}
\end{array}\right\} .
$$

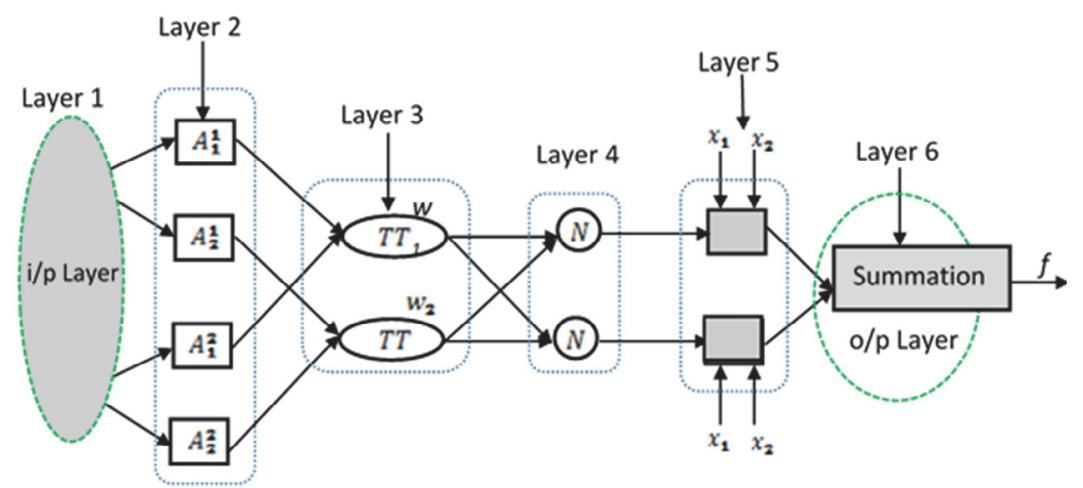

Fig. 2. ANFIS diagram with six layers

$$
\left.\begin{array}{l}
L L_{3 i}=W_{i}=U_{a g}\left(x_{i}\right), U_{B g}\left(x_{i}\right), U_{C g}\left(x_{i}\right), U_{C g}\left(x_{i}\right) ; \\
\text { For } i=1, \ldots,\left(q_{1}+q_{2}+q_{3}+q_{4}\right) ; \\
g g=1, \ldots, \sum_{i=1}^{4} q_{i} \quad \text { and } \quad r_{f}=q_{1} * q_{2} * q_{3} * q_{4}
\end{array}\right\},
$$




$$
\begin{gathered}
L L_{4 i}=\bar{W}_{i} f_{i}=\frac{W_{i}}{\sum_{f} W_{r}}, \\
L L_{5 i}=\bar{W}_{i f_{i}}=\bar{W}_{i}\left(p_{i} x_{1}+r_{i} x_{1}+s_{i} x_{3}+t_{i} x_{4}+u_{i}\right), \\
L_{6 i}=\sum_{r=1}^{r_{f}} \bar{W}_{i} f_{i}=\frac{\sum_{i=1}^{i=1} \bar{W}_{i}}{\sum_{f} W_{i}} . \\
i=1
\end{gathered}
$$

Figure 2 illustrates the overall structure of the ANFIS control for any plant management. This hybrid ANFIS controller works with an old style controller. It uses the control law that pushes the ultimate responder of the console to an ideal position and takes the proposed estimation procedure. The console has six common control components; each conventional ANFIS controller must be used across a strain. All ANFIS controllers have a similar structure and get comparative change and aptitude for standards. The ANFIS console chassis contains unclear fragments of FIS after the least NN squared. The frame structure constitutes a large number of units (and affiliations) coordinated in five related configuration layers (L1 to L5) as follows:

L1: Contains input factors (investment limits), for example, inputs 1 and 2. The triple or costly MF can be used. This layer provides data related to xi for the accompanying layer. There exist two data sources (botch signal and bungle eer $(\mathrm{k})$ ) that are determined via equation (12). The point joint aid and its change are used as an analysis of the components inventory and their subsequent use in the control law by equation (11):

The enrollment capacities expressed here as A, B, C, and D are ringer molded capacities and characterized through equation (27).

All the changes given in various types of the ring formed limit, differing and according to the educational assortment for the issue considered caused by the fuzzy interesting parameters work for the different values of the parameters $\mathrm{a}_{\mathrm{g}}, \mathrm{b}_{\mathrm{g}}$, and $\mathrm{c}_{\mathrm{g}}$.

L2 (Attention Layer): Checks the weight of each recruiting action. Inputs with respect to xi are received from the initial layer, where the investment work of each cushy game plan is done for individual data factors, and recruitment indicates that it decides the degree to which the ninth entry has a spot with the set of feathers that contribute to the accompanying layer. 
L3 (Standard Layer): Every neuron currently regulates feathered bases; each action is a starting level for each criterion. Each central point of the classes is marked by institutional burdens.

L4 (Defragmentation Layer): Gives upcoming yield greetings in the light of the rules conclusion. The relationship between the layers is weighted by the lined mono sole that addresses another plan for the parameters of the soft nervous frame.

L5 (Production Layer): All information sources beginning with Layer 4 are abbreviated and change the results of direct aggregation into slides. The ANFIS structure is usually adjusted by estimating the least squares and calculating the posterior propagation to estimate the coefficient of interest. The estimate above is used with six ANFIS controllers that control various parameters of the controller.

$$
\begin{aligned}
& \mu_{A g}(x)=\frac{1}{1+\left\{\left(\frac{x-c_{g}}{a_{g}}\right)^{2}\right\}^{b_{g}}} ; g=1 \text { to } q_{1} \\
& \mu_{B g}(x)=\frac{1}{1+\left\{\left(\frac{x-c_{g}}{a_{g}}\right)^{2}\right\}^{b_{g}}} ; g=q_{1}+1 \text { to } q_{1}+q_{2} \\
& \mu_{B g}(x)=\frac{1}{1+\left\{\left(\frac{x-c_{g}}{a_{g}}\right)^{2}\right\}^{b_{g}}} \text {; } \\
& g=q_{1}+q_{2}+1 \text { to } q_{1}+q_{2}+q_{3} \\
& \mu_{B g}(x)=\frac{1}{1+\left\{\left(\frac{x-c_{g}}{a_{g}}\right)^{2}\right\}^{b_{g}}} \text {; } \\
& g=q_{1}+q_{2}+q_{3}+1 \text { to } q_{1}+q_{2}+q_{3}+q_{4}
\end{aligned}
$$

The ANFIS controller and the customary controller yields are included. Post-starting, the planning of the parameters is acclimated to the ANFIS controller parameters as demonstrated by fleecy alteration getting ready standards (explained straightaway). 


\section{Design of 7-DOF Human Manipulator Based on Virtual Re-}

ality. The structure prerequisites with VRML are clarified by restricted handling assumptions, freedom, steady self-enlistment, responsibility; every fashioner ought to think about these focuses. A clarification of the structure methods will be given in VRML. The VRML configuration relies upon the fashioner's data and the picture of the article. There are two alternatives for planning in a computer generated reality: the first one is a standard arrangement, for instance, ball, table, roller etc, and the subsequent choice is a free structure by choosing the recorded face set one is to form numerous setups by free reorder focuses. Any structure is in this manner a genuine structure as in the subsequent choice. The subsequent choice begins with building these parts in a steady progression and confirms the state of the applicable genuine moving part.

These processor' pieces cannot be imitated in a computer generated reality, and the standard arrangement is utilized in the augmented simulation library. The organization is not the same along these lines; the structure is accomplished utilizing the recorded face target set in a computer generated real model. The subsequent choice in the plan is significant, as the association between all pieces of the structure will be accomplished for the last item, and the beginning of the article must be resolved. Speaking about the beginning stage of the plan, ITS undertaking is finished by choosing the principal shape (e.g., the standard), and afterward interfacing of the following shape (the subsequent joint) to the Kids catch and utilizing a similar methodology with different elements. Figure 3 shows the overall 7-DOF human manipulator as a human arm form.

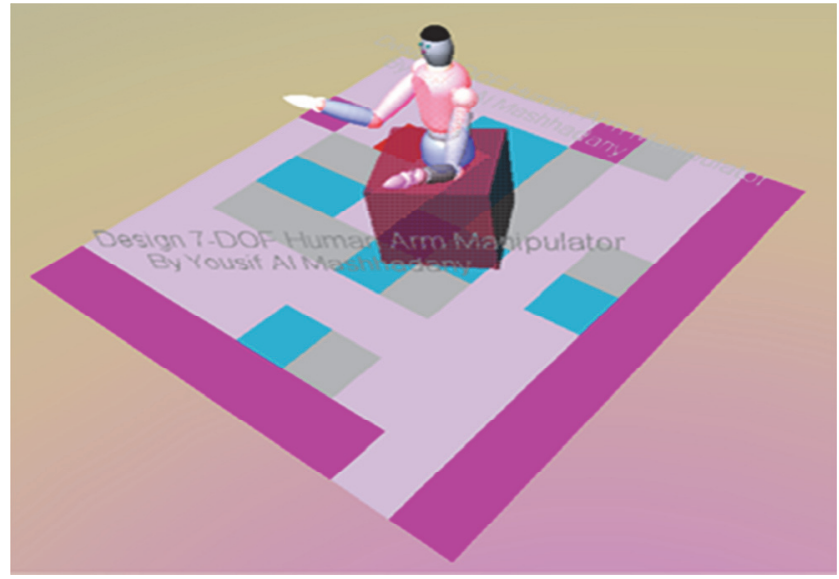

Fig. 3. Design and implementation of 7-DOF human manipulator by VR technique 
5. Design of Hybrid Intelligent Controller. The structure of an intelligent controller of the human manipulator as 7-DOF model depends on the ANFIS design. In this work it is actually identified with a genuine estimations of framework parameters, considering the real restriction of the human arm joints as indicated by the subtleties. The joint motor is a genuine motor viewed as a vehicle working as in condition (1).

$$
T . F_{m}(s)=\frac{k}{s^{2}+16 s+24} ; \quad k>0 .
$$

Presentation of the square chart of the control framework which describes in detail (see Fig. 4) commitments for system structure that has twoway bearing that present $\left(\mathrm{TT}_{1}, \mathrm{TT}_{2}, \mathrm{TT}_{3}\right)$ and the final target position limited by $\left(T_{x}, T_{y}, T_{z}\right)$. In this method, every joint in manipulator structure will be controlled separately; as the network for seven controllers is used, all the system design will prepare the controlling signal with vectors $(\delta)$. The execution of the order will be done according to practical assumptions for a human arm.

The prepared calculation contains contributions for wanted estimations of the point separator and the real estimations of these edges. The ideal qualities are determined utilizing the investigative arrangement of the IKP calculation shown up in the previous components. The real estimations of all joint edges receive remarks from initial structure operated with VR innovation.

The ANFIS controller was simulated by Matlab Ver. 2019b programming Ver.2019b, with two sources of infomation, a mistake sign, and a change in the blunder. The fluffy derivation technique was developed by Mamdani and utilized on the grounds, that it is instinctive, broadly acknowledged, and appropriate to real system info, and, for this system design, it gives preferable outcomes versus Sugeno deduction strategy (see Fig. 5).

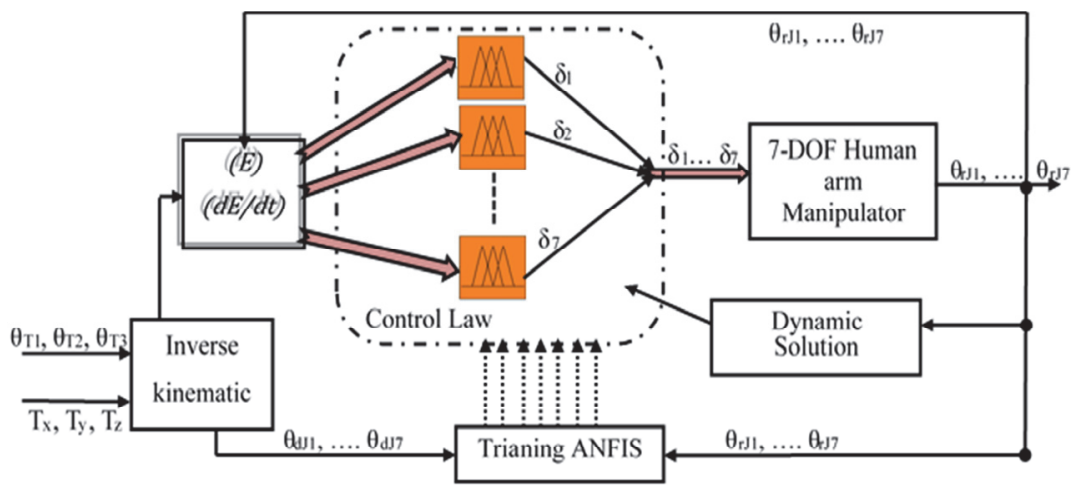

Fig. 4. Structure of intelligent controller with system design 


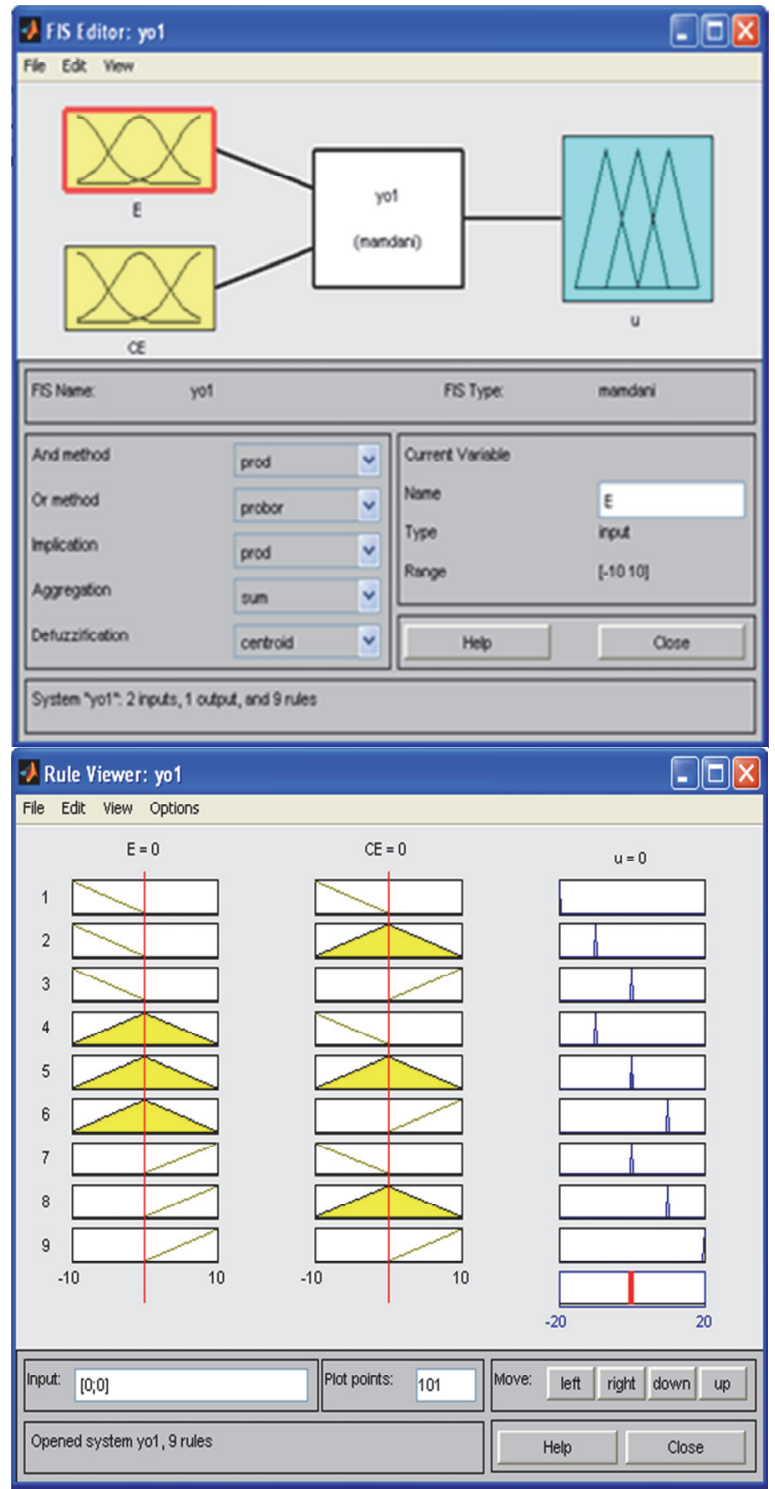

Fig. 5. Training rules of the ANFIS controller based on Mamdani's fuzzy inference

In planning the controller, kinds of participation capacities were attempted before choosing the best: triangular inherent enrollment work (trimf). 
The experimental configuration of the ANFIS controller, i.e., choosing an impedance category, the participation work style, and the quantity of the enrollment work at a shrouded stage, gave ideal outcomes: least number of rules and straightforward reproduction. A plan utilizes seven equal associated ANFIS to process an ideal avoidance for joints and give the ideal edge. Figure 6 shows the method of the Matlabfuzzy tool based on compartment structure.

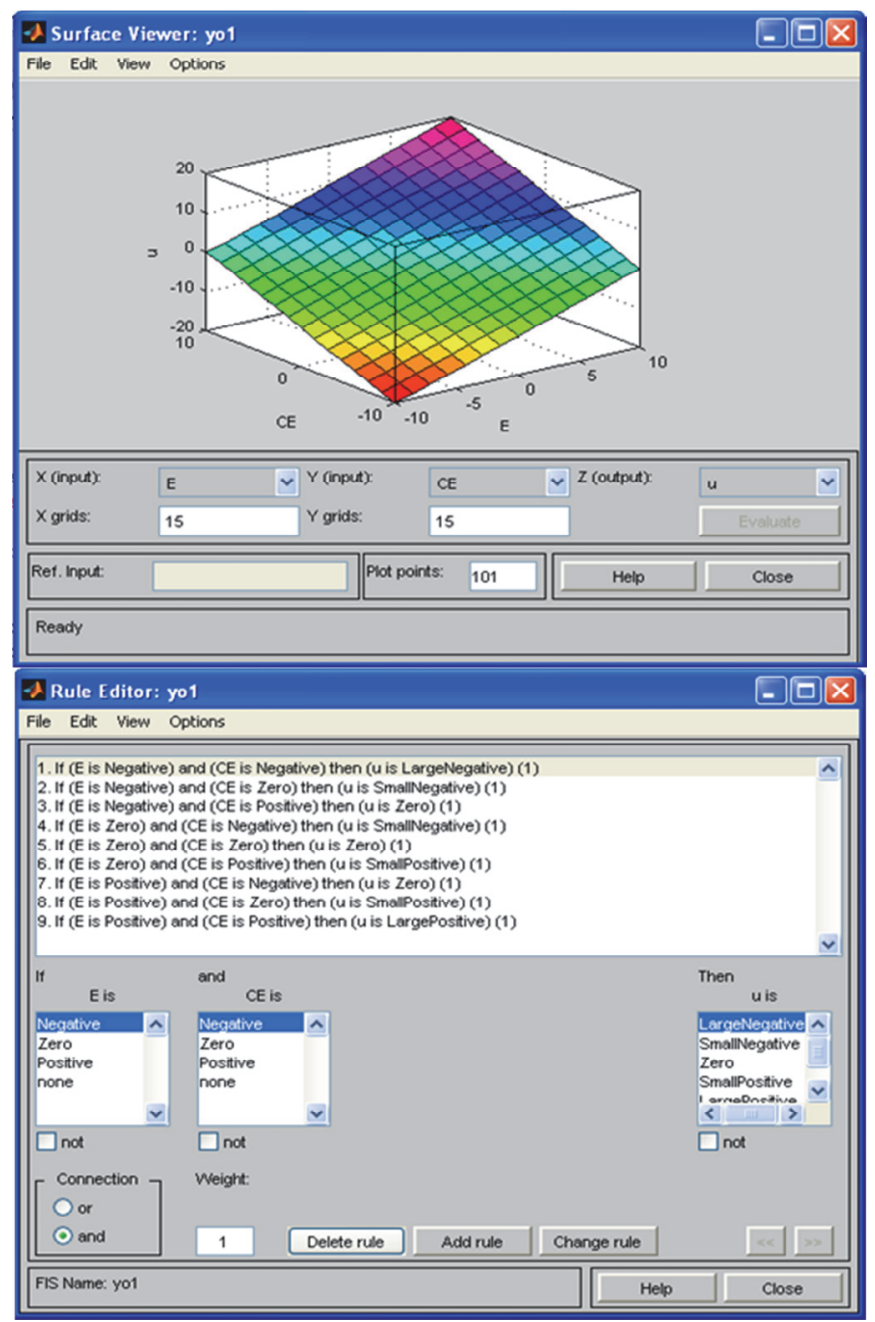

Fig. 6. Testing for ANFIS (off-line form) controller with surface error

Труды СПИИРАН. 2020. Том 19 № 4. ISSN 2078-9181 (печ.), ISSN 2078-9599 (онлайн) 
6. Simulation and Testing of System Design. A simulation of this design is shown in Figure 7, a virtual reality design control diagram. The human arm is a complex and nonlinear system and has multiple interactions in the movements for which each joint is responsible. So, to control this movement and implement it accurately is needed the use of seven networks of ANFIS controllers to execute all the movements of the human arm accurately. Training for these networks was built on the basis of the practical data of these movements, accounting for all practical limitations in implementing the movements.

The controlling rules were produced using nine principles by setting standards for them using the ANN system. The exact value of the joint sites is returned by the back signal, and then the new command is calculated based on the error signal that is calculated by comparing the calculated site with the actual site. Moving to the second location in the path, except for obtaining the required accuracy, the delay achieved through high speed was overcome at calculating the final value that characterizes the ANFIS system. Conventional controller data (PID) were used as starting points for smart rulers. Results and construction of these controllers can be seen in Figure 7.

By examining this design for several different tracks of the arm and for implementing different tasks such as rotation and complex threedimensional movements, it can be concluded that the performance of double units between the traditional control system PID and smart controls ANFIS has accurate, rapid and reliable results in building complex systems intended for industrial applications. Figure 8 presents detailed steps used to produce orders in controllers and the final results obtained.

The commands in the controls are produced via Simulink / Matlab by applying the algorithm built for these controls. The link between the human arm models was built using VR. This model is operated with the program instructions prepared by the designer. The design was tested by performing different movements like twisting/elbow expansion, elbow rotation; shoulder snatching, flexion/shoulder augmentation, ulnar/spiral drift, ebb and flow/flat augmentation of the shoulder, all above postures shown in Figure 9.

Control and reenactment of the human control arm have been implemented currently. The joystick is collected first; at this point it is replaced by an additional correspondence and control interface card. Reproduction manipulator and similarly generated computer experience model. The convergence between the reproductive robot and the original robot is confirmed by the use of distinct bookmarks. The results gave worthy feedback with the ANFIS controller. The projects were executed by graphical user interface (GUI). 


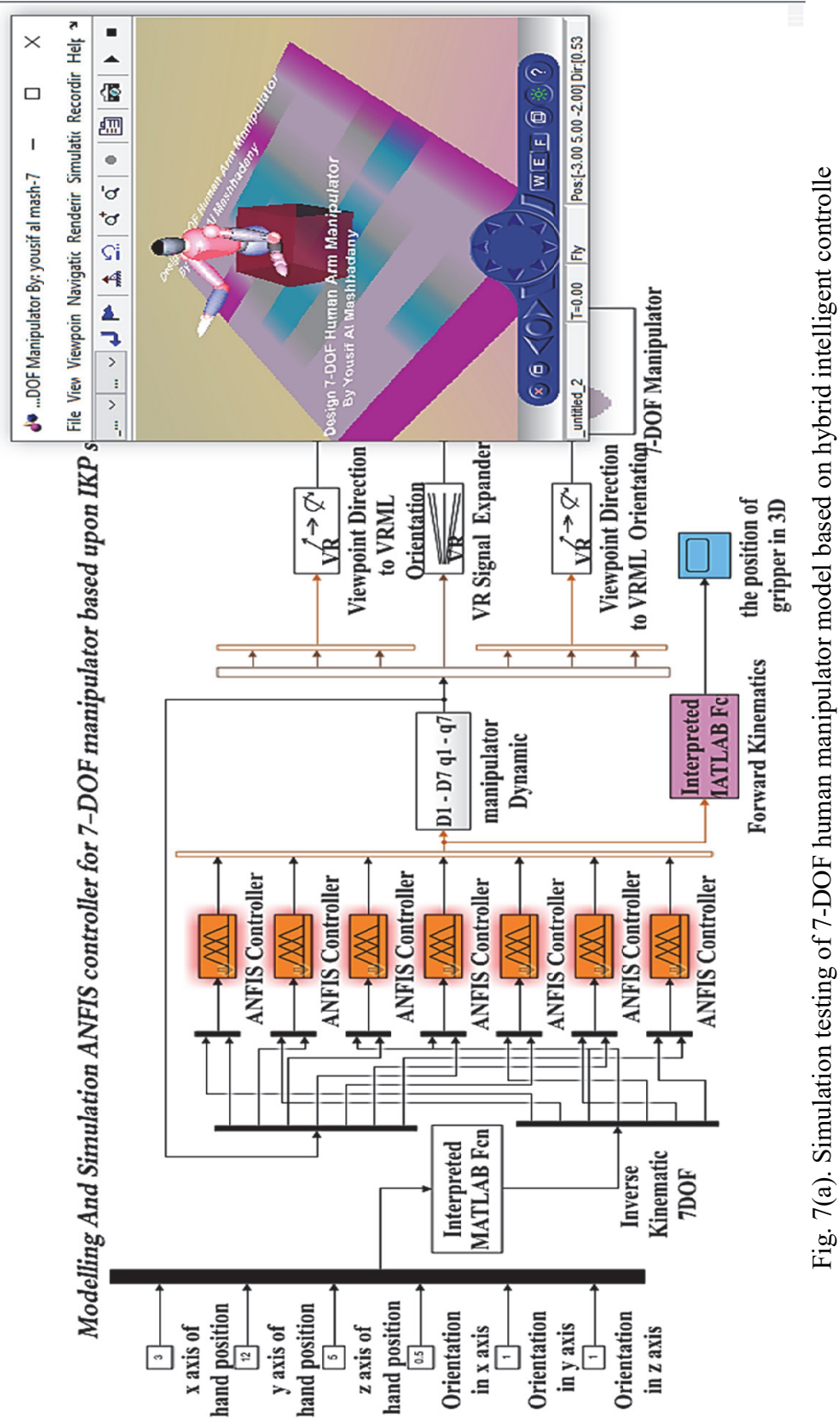

Труды СПИИРАН. 2020. Том 19 № 4. ISSN 2078-9181 (печ.), ISSN 2078-9599 (онлайн) 793 www.proceedings.spiiras.nw.ru 


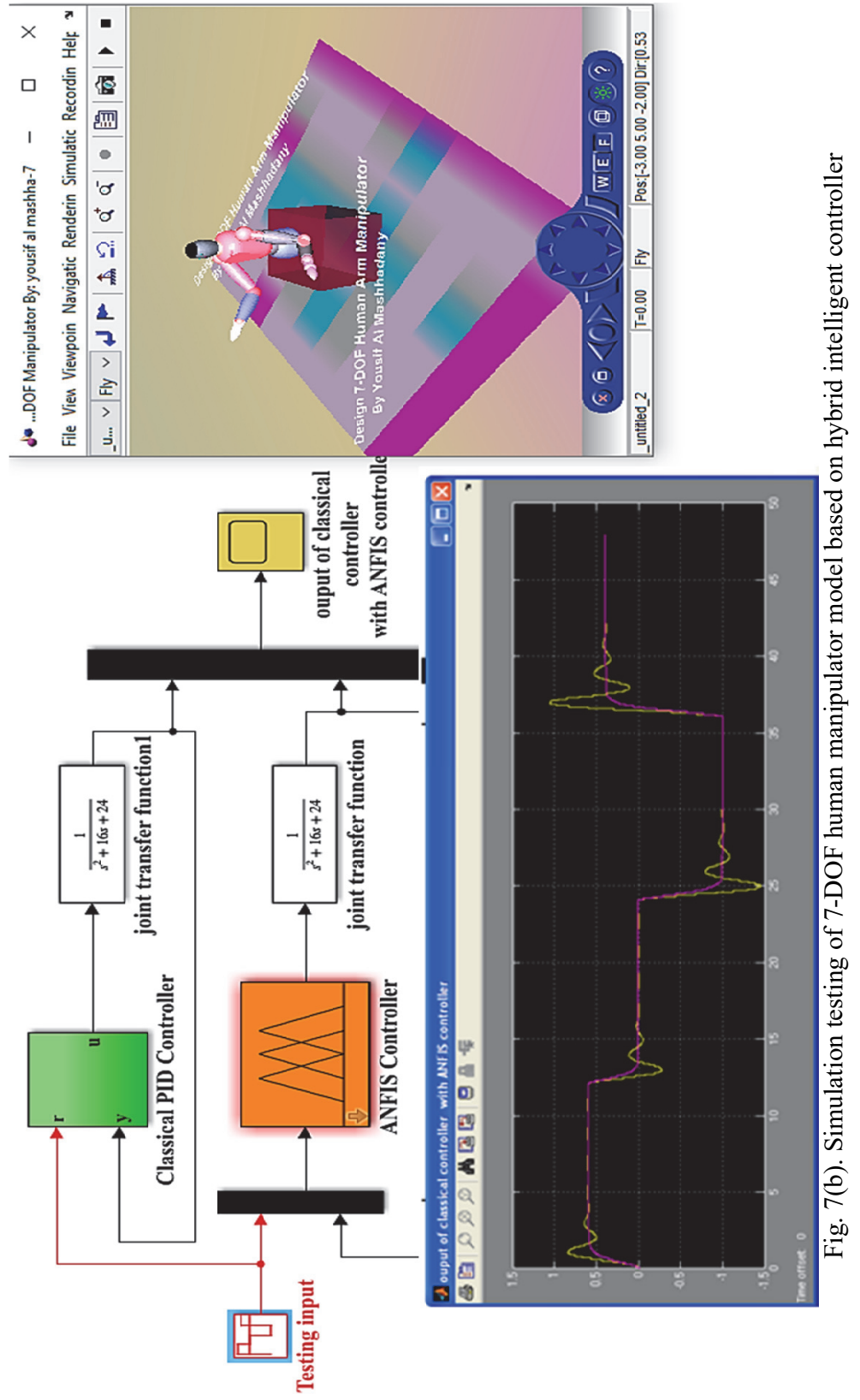

794 SPIIRAS Proceedings. 2020. Vol. 19 No. 4. ISSN 2078-9181 (print), ISSN 2078-9599 (online) www.proceedings.spiiras.nw.ru 


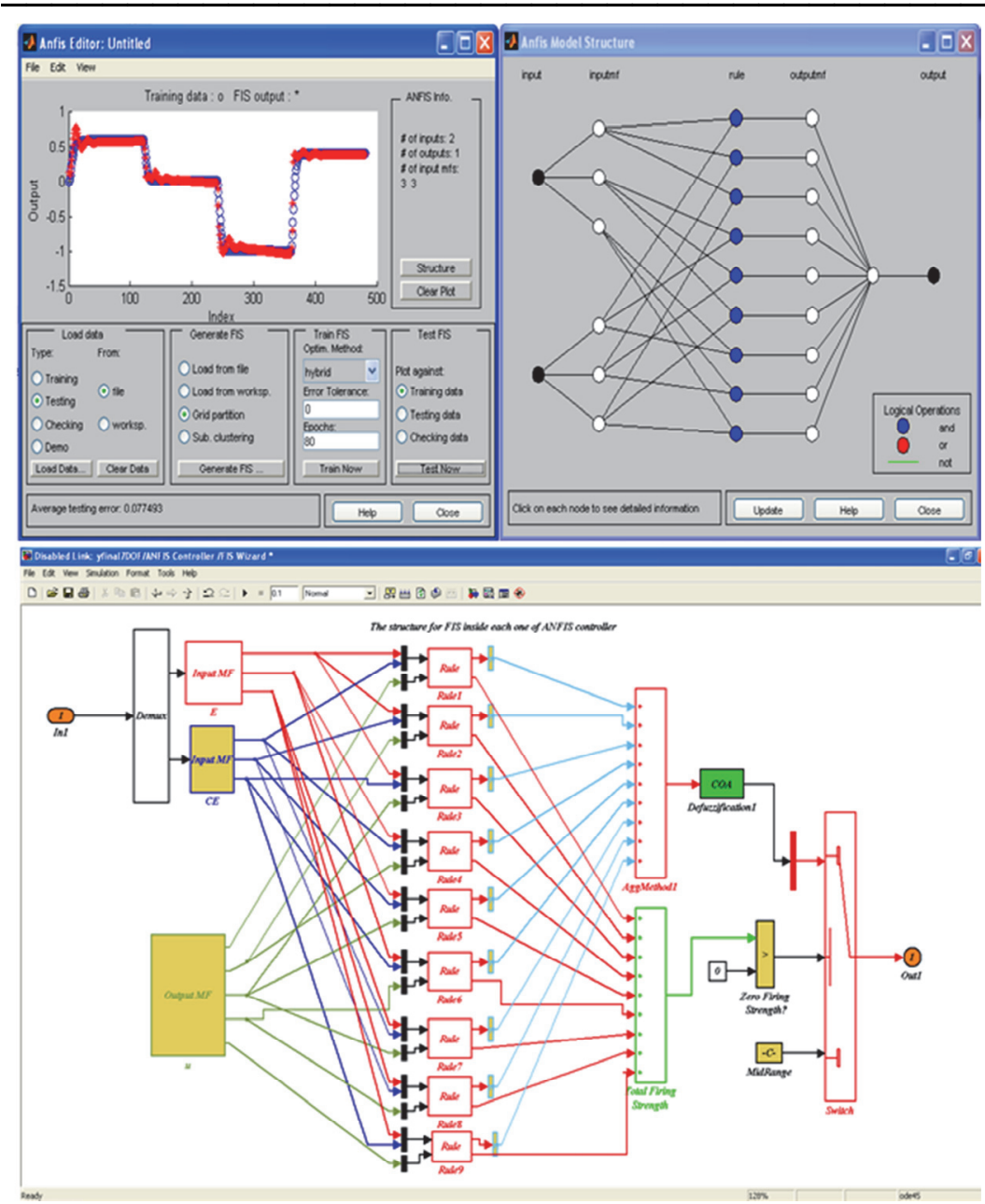

Fig. 8. GUI Matlab for ANFIS training and construction

Various contextual investigations are presented. Instructions are directed to various methods and show the trend of all watched joints. The amplitude of the multiple boundaries was marked by the method. There was a need for polynomial request to ensure a smooth increase in knuckle movement speed. The results indicate that significant implementation made contact reactions faster. Therefore, new trends can possibly be envisioned depending on the customers' requirements. The following computerized thinking methods will be applied to the robot architecture for better performance after the traits. 


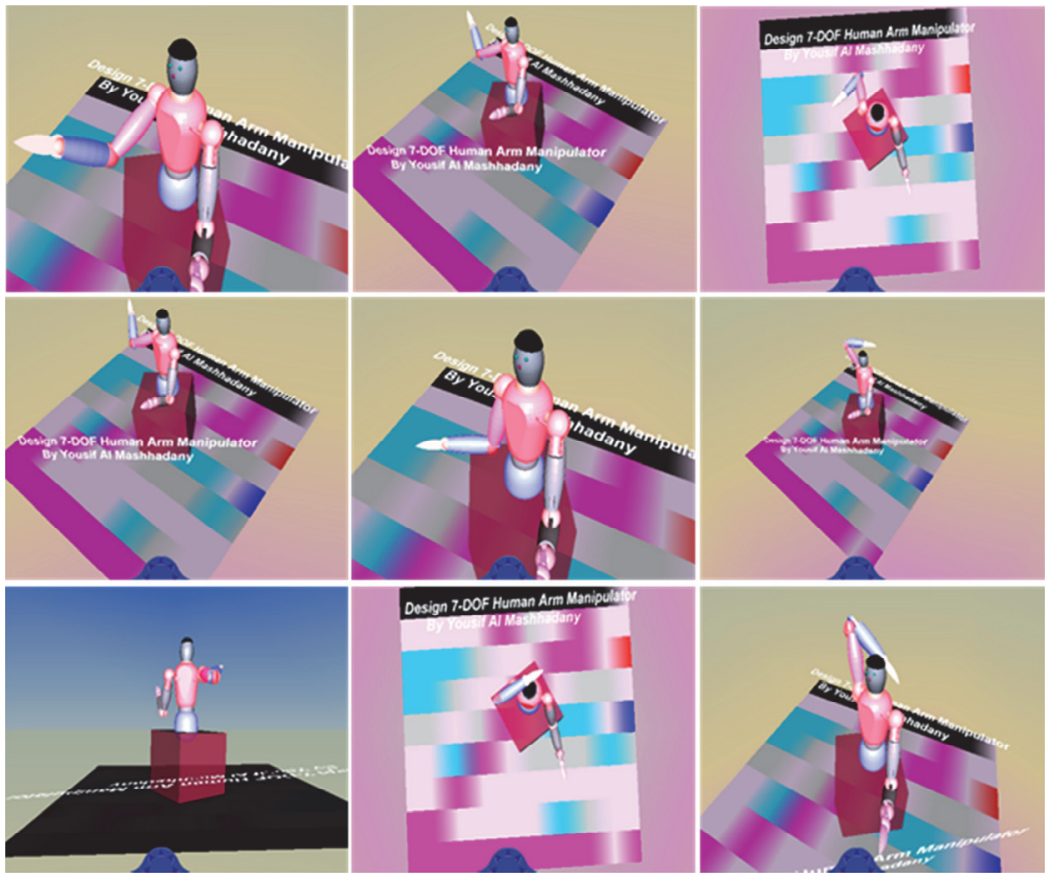

Fig. 9. The implementation of different postures for 7-DOF human manipulator model based on hybrid intelligent controller

7. Conclusion. The main goal of using smart controls of all kinds is to get rid of the linear systems' persisting problems, especially in dynamic systems. In this work, quite a precise hybrid intelligent controller was designed through using the ANFIS units, which depend on the accuracy of work based on eliminating all obscure obstacles at performance. The system administrator needs a high accuracy in training and examining all types of tracks that the arm can implement and store data for these measures. Comparing the results of traditional PID controls and smart controllers, depending on the hybrid installation that was used, it can be seen that the results of smart controls are highly accurate and fast, and they can perform broad tasks by increasing paths' accuracy. It can also be observed that the combination of the FIS system and the neural network system has given these controllers additional strength to deal with nonlinear interference in many complex movements that resulted in mixing more than one joint at the same time. The ANFIS control units with hybrid systems contribute to increasing the efficiency of these controllers' performance and accomplishing complex tasks by relying on the calculations' accuracy and the ability to address the 
disturbances that occur during the performance of dynamic systems. Therefore, the use of hybrid control units on the basis of ANFIS units could be recommended for complex and important applications like surgical procedures and production lines for small objects in laboratories.

\section{References}

1. Rosen E. et al. Testing robot teleoperation using a virtual reality interface with ROS reality. Proceedings of the 1st International Workshop on Virtual, Augmented, and Mixed Reality for HRI (VAM-HRI). 2018. pp. 1-4.

2. Prabu D., Kumar S., Prasad R. Advanced Dynamic Path Control of the Three Links SCARA using Adaptive Neuro Fuzzy Inference System. Robot Manipulators, Trends and Development. 2010. pp. 399-412.

3. Katzschmann R.K. Building and Controlling Fluidically Actuated SoftRobots: From Open Loop to Model-based Control. Massachusetts Institute Of Technology. 2018. pp. 247-272.

4. Tayebihaghighi S., Piltan F., Kim J.M. Control of an Uncertain Robot Manipulator Using an Observation-based Modified Fuzzy Sliding Mode Controller. International Journal of Intelligent Systems and Applications. 2018. vol. 10. no. 3. pp. 41-49.

5. Mahmoodabadi M.J., Ziaei A. Inverse Dynamics Based Optimal Fuzzy Controller for a Robot Manipulator via Particle Swarm Optimization. Journal of Robotics. 2019. vol. 2019. $10 \mathrm{p}$.

6. Al-Mashhadany Y.I. MIEEE H. E. ANFIS-Inverse-Controlled PUMA 560 Workspace Robot with Spherical Wrist. Procedia Engineering. 2012. vol. 41. pp. 700-709.

7. Ahmed M.N., Veladri K. Modeling and Simulation of 7-dof Robotic Manipulator. National Conference on Technological Advancements in Mechanical Engineering. 2016. pp. 303-309.

8. Al-Mashhadany Y.I. Modeling and Simulation of Adaptive Neuro-Fuzzy Controller for Chopper-Fed DC Motor Drive. 2011 IEEE applied power electronic colloquium (IAPEC). 2011. pp. 110-115.

9. Gorobtsov A.S. et al. [Features of solving the equations of the inverse problem method for the synthesis of stable controlled motion of walking robots]. Trudy SPIIRAN SPIIRAS Proceedings. 2019. vol. 18(1). pp. 85-122. (In Russ.).

10. Al-Mashhadany Y.I. A Posture of 6-DOF Manipulator By Locally Recurrent Neural Networks (LRNNs) Implement in Virtual Reality. 2010 IEEE Symposium on Industrial Electronics and Applications (ISIEA). 2010. pp. 573-578.

11. Klimchik A., Pashkevich A. Robotic manipulators with double encoders: accuracy improvement based on advanced stiffness modeling and intelligent control. IFAC-Papers OnLine. 2018. vol. 51. no. 11. pp. 740-745.

12. Shahri A.R.M., Khoshravan H., Naebi A. Design ping-pong player robot controller with ANFIS. 2011 Third International Conference on Computational Intelligence, Modelling \& Simulation. 2011. pp. 165-169.

13. He Y.et al. Dynamic Modeling, Simulation, and Experimental Verification of a Wafer Handling SCARA Robot With Decoupling Servo Control. IEEE Access. 2019. vol. 7. pp. 47143-47153.

14. Alferov G., Ivanov G., Efimova P., Sharlay A. Study on the Structure of Limit Invariant Sets of Stationary Control Systems with Nonlinearity of Hysteresis Type. AIP Conference Proceedings. 2017. vol. 1863. no. 1. pp.080003.

15. Ivanov G.G., Sharlay A.S. On stability of linear homogeneous switched systems. 2015 International Conference "Stability and Control Processes" in Memory of V.I. Zubov (SCP). 2015. pp. 13-15.

16. Andreev V.P., Pletenev P.F. [The method of information interaction for distributed control systems in robots with a modular architecture]. Trudy SPIIRAN - SPIIRAS Proceedings. 2018. vol. 2(57). pp. 134-160. (In Russ.). 
17. Mahmoodabadi M.J., Baghini A.Y. Design of an Optimal Fuzzy Controller of an UnderActuated Manipulator Based on Teaching-Learning-Based Optimization. Acta mechanica et automatica. 2019. vol. 13. no. 3. pp. 166-172.

18. Busson D., Bearee R., Olabi A. Task-oriented rigidity optimization for 7-DOF redundant manipulators. IFAC-PapersOnLine. 2017. vol. 50. no. 1. pp. 14588-14593.

19. Kulakov F., Kadry S., Alferov G., Sharlay A. Bilateral Remote Control over Space Manipulators. AIP Conference Proceedings. 2018. vol. 2040. no. 1. pp. 150015.

20. Cen L., Melkote S.N. Effect of Robot Dynamics on the Machining Forces in RoboticMilling. Procedia Manufacturing. 2017. vol. 10. pp. 486-496.

21. Arkhipov V.V., Naumov V.B. [Artificial intelligence and autonomous devices in the context of law: on the development of Russia's first law on robotics]. Trudy SPIIRAN SPIIRAS Proceedings. 2017. vol. 6(55). pp. 46-62. (In Russ.).

22. Di Vito D., Natale C., Antonelli G. A Comparison of Damped Least Squares Algorithms for Inverse Kinematics of Robot Manipulators. IFAC-PapersOnLine. 2017. vol. 50. no. 1. pp. 6869-6874.

23. Faria C. et al. Position-based kinematics for 7-DoF serial manipulators with global configuration control, joint limit and singularity avoidance. Mechanism and Machine Theory. 2018. vol. 121. pp. 317-334.

24. Kumar P.B., Verma N.K., Parhi D.R., Priyadarshi D. Design and control of a 7 DOF redundant manipulator arm. Australian Journal of Mechanical Engineering. 2019. vol. 73. pp. 1-12.

25. Me M.N.A., Veladri K. Modeling and Simulation of 7-dof Robotic Manipulator. National Conference on Technological Advancements in Mechanical Engineering. 2016. pp. 303-309.

26. Faria C. et al. Review of Robotic Technology for Stereotactic Neurosurgery. IEEE Reviews in Biomedical Engineering. 2015. vol. 8. pp. 125-137.

27. Sutyasadi P., Parnichkun M. Gait Tracking Control of Quadruped Robot Using Differential Evolution Based Structure Specified Mixed Sensitivity Robust Control. Journal of Control Science and Engineering. 2016. vol. 2016. pp. 1-17.

28. Kobayashi T. et al. Adaptive speed controller using swing leg motion for 3-D limitcyclebased bipedal gait. Nonlinear Dynamics. 2016. vol. 84. no. 4. pp. 2285-2304.

29. Garbi G.P. Multivalued Adaptive Neuro-Fuzzy Controller for Robot Vehicle. International Conference on Intelligent Systems and Knowledge Engineering. 2007.

30. Singh M.K, Parhi D.R, Pothal J.K. ANFIS Approach for Navigation of Mobile Robots. 2009 International Conference on Advances in Recent Technologies in Communication and Computing. 2009. pp.727-731.

31. Shieh M.Y. et al. ANFIS based Controller Design for Biped Robots. 2007 IEEE Proceedings of International Conference on Mechatronics. 2007. pp. 1-6.

32. Xia K. et al. Virtual Decomposition Based Modeling for Multi-DOF Manipulator With Flexible Joint. IEEE Access. 2019. vol. 7. pp. 91582-91592.

33. Silawatchananai C., Parnichkun M. Haptics control of an arm exoskeleton for virtual reality using PSO-based fixed structure H1 control. International Journal of Advanced Robotic Systems. 2019. vol. 16. no. 3. pp. 1-15

34. Al Mashhadany Y., Gaeid K.S., Awsaj M.K. Intelligent Controller for 7-DOF Manipulator Based upon Virtual Reality Model. 2019 12th International Conference on Developments in eSystems Engineering (DeSE). 2019. pp. 687-692.

35. Budiharto W., Jazidie A., Purwanto D. Indoor Navigation using Adaptive Neuro Fuzzy Controller for Servant Robot. 2010 Second International Conference on Computer Engineering and Applications. 2010. vol. 1. pp. 582-586.

36. Luecke G.R. Haptic Interactions Using Virtual Manipulator Coupling with Applications to Underactuated Systems. IEEE transactions on robotics. 2011. vol. 27. no. 4. pp. 730-740. 
37. Malafeyev O., Alferov G., Andreyeva M. Group strategy of robots in game-theoretic model of interception with incomplete information. 2015 International Conference on Mechanics-Seventh Polyakhov's Reading. 2015. pp. 1-3.

38. Muslim M.A., Rusli M., Zufaryansyah A.R., Ibrahim B.S.K.K. Development of a quadruped mobile robot and its movement system using geometric-based inverse kinematics. Bulletin of Electrical Engineering and Informatics. 2019. vol. 8. no. 4. pp. 1224-1231.

39. Lin N.I., Lee C.S. Measurement of the Robot Motor Capability of a Robot Motor System: A Fitts's-Law-Inspired Approach. Sensors. 2013. vol. 13(7). pp. 8412-8430.

40. Al-Mashhadany. Y.I. Modeling and Simulation of Adaptive Neuro-Fuzzy Controller for Chopper-Fed DC Motor Drive. 2011 IEEE Applied Power Electronics Colloquium (IAPEC). 2011. pp. 110-115.

41. Lopez-Franco C. et al. Inverse kinematics of mobile manipulators based on differential evolution. International Journal of Advanced Robotic Systems. 2018. vol. 15. no. 1. pp. 1-22.

42. Alferov G.V., Malafeyev O.A., Maltseva A.S. Game-theoretic model of inspection by anticorruption group. AIP Conference Proceedings. 2015. vol. 1648. no. 1. pp. 450009.

43. Hussien A.A. et al. DTC Controller Variable Speed Drive of Induction Motor with Signal Processing Technique. 2019 12th International Conference on Developments in eSystems Engineering (DeSE). 2019. pp. 681-686.

44. Ivanov G., Alferov G., Sharlay A., Efimova P. Conditions of Asymptotic Stability for Linear Homogeneous Switched System. AIP Conference Proceedings. 2017. vol. 1863. no. 1.pp. 080002.

Al Mashhadany Yousif Ismail - Ph.D., Associate Professor, Lecturer, Electrical Engineering Department of College of Engineering, University Of Anbar. Research interests: 7-DOF Manipulator, Human Manipulator, Intelligent Controller, Virtual Reality Model, Artificial Neural Network (ANN). The number of publications - 72. yousif_phd@hotmail.com; 11, Ramadi, Iraq; office phone: 009647824643998. 


\section{Ю.И. АЛЬ МАШХАДАНИ \\ ДИЗАЙН И АНАЛИЗ ЧЕЛОВЕКОПОДОБНОГО \\ МАНИПУЛЯТОРА С СЕМЬЮ СТЕПЕНЯМИ СВОБОДЫ НА ОСНОВЕ ГИБРИДНОГО ИНТЕЛЛЕКТУАЛЬНОГО КОНТРОЛЛЕРА}

Аль Машхадани Ю.И. Дизайн и анализ человекоподобного манипулятора с семью степенями свободы на основе гибридного интеллектуального контроллера.

Аннотация. Представлено взаимодействие с 3D-моделями в среде виртуальной реальности (ВР), которое соотносится с движением реальной руки человека. Точность позиционирования достигается благодаря обратной связи. Ключевую роль в поиске оптимальных значений управляющих сигналов играет адаптивная нейро-нечеткая система вывода (Adaptive Network-based Fuzzy Inference System, ANFIS), сочетающая в себе преимущества нейронных сетей (NN) и нечеткой логики (fuzzy logic, FL).

Данный подход дает точные результаты при добавлении обучающей сигнальной системы к комбинированной обучающей базе, используемой при объединении метода пропорций наклона; ошибка наименьших квадратов (LSE) подготавливает ANFIS к любым фреймворкам. Контроллер на основе ANFIS был применён к робототехнической системе с семью степенями свободы, модель которого была разработана в виртуальной реальности, воспроизводящей системные конструкции через Matlab/Simulink, чтобы соединить ВР-модель с инструкцией для выполнения команд гибридным интеллектуальным контроллером на основе технологии ANFIS. Данная усовершенствованная процедура при внедрении полученных результатов показывает возможность практического использование предлагаемой системы контроллера.

Ключевые слова: человекоподобный манипулятор, гибридный интеллектуальный контроллер, виртуальная реальность, искусственные нейронные сети.

Аль Машхадани Юсиф Исмаил - Ph.D., доцент, преподаватель, кафедра электротехники инженерного колледжа, Университет Анбара. Область научных интересов: манипулятор с семью степенями свободы, человеческий манипулятор, интеллектуальный контроллер, модель виртуальной реальности, искусственная нейронная сеть (ИНС). Число научных публикаций —72. yousif phd@hotmail.com; 11, Эр-Рамади, Ирак; р.т.: 009647824643998.

\section{Литература}

1. Rosen E. et al. Testing robot teleoperation using a virtual reality interface with ROS reality // Proceedings of the 1st International Workshop on Virtual, Augmented, and Mixed Reality for HRI (VAM-HRI). 2018. pp. 1-4.

2. $\quad$ Prabu D., Kumar S., Prasad R. Advanced Dynamic Path Control of the Three Links SCARA using Adaptive Neuro Fuzzy Inference System // Robot Manipulators, Trends and Development. 2010. pp. 399-412.

3. Katzschmann R.K. Building and Controlling Fluidically Actuated SoftRobots: From Open Loop to Model-based Control // Massachusetts Institute Of Technology. 2018. pp. 247-272.

4. Tayebihaghighi S., Piltan F., Kim J.M. Control of an Uncertain Robot Manipulator Using an Observation-based Modified Fuzzy Sliding Mode Controller // International Journal of Intelligent Systems and Applications. 2018. vol. 10. no. 3. pp. 41-49.

5. Mahmoodabadi M.J., Ziaei A. Inverse Dynamics Based Optimal Fuzzy Controller for a Robot Manipulator via Particle Swarm Optimization // Journal of Robotics. 2019. vol. 2019. 10 p.

6. Al-Mashhadany Y.I. MIEEE H. E. ANFIS-Inverse-Controlled PUMA 560 Workspace Robot with Spherical Wrist // Procedia Engineering. 2012. vol. 41. pp. 700-709. 
7. Ahmed M.N., Veladri K. Modeling and Simulation of 7-dof Robotic Manipulator // National Conference on Technological Advancements in Mechanical Engineering. 2016. pp. 303-309.

8. Al-Mashhadany Y.I. Modeling and Simulation of Adaptive Neuro-Fuzzy Controller for Chopper-Fed DC Motor Drive // 2011 IEEE applied power electronic colloquium (IAPEC). 2011. pp. 110-115.

9. Горобцов А.С. и др. Особенности решения уравнений метода обратной задачи для синтеза устойчивого управляемого движения шагающих роботов // Труды СПИИРАН. 2019. Т. 18(1). С. 85-122.

10. Al-Mashhadany Y.I. A Posture of 6-DOF Manipulator By Locally Recurrent Neural Networks (LRNNs) Implement in Virtual Reality // 2010 IEEE Symposium on Industrial Electronics and Applications (ISIEA). 2010. pp. 573-578.

11. Klimchik A., Pashkevich A. Robotic manipulators with double encoders: accuracy improvement based on advanced stiffness modeling and intelligent control // IFACPapers OnLine. 2018. vol. 51. no. 11. pp. 740-745.

12. Shahri A.R.M., Khoshravan H., Naebi A. Design ping-pong player robot controller with ANFIS // 2011 Third International Conference on Computational Intelligence, Modelling \& Simulation. 2011. pp. 165-169.

13. He Y.et al. Dynamic Modeling, Simulation, and Experimental Verification of a Wafer Handling SCARA Robot With Decoupling Servo Control // IEEE Access. 2019. vol. 7. pp. 47143-47153.

14. Alferov G., Ivanov G., Efimova P., Sharlay A. Study on the Structure of Limit Invariant Sets of Stationary Control Systems with Nonlinearity of Hysteresis Type // AIP Conference Proceedings. 2017. vol. 1863. no. 1. pp.080003.

15. Ivanov G.G., Sharlay A.S. On stability of linear homogeneous switched systems // 2015 International Conference "Stability and Control Processes" in Memory of V.I. Zubov (SCP). 2015. pp. 13-15.

16. Андреев В.П., Плетенев П.Ф. Метод информационного взаимодействия для систем распределённого управления в роботах с модульной архитектурой // Труды СПИИРАН. 2018. Вып. 2(57). С. 134-160.

17. Mahmoodabadi M.J., Baghini A.Y. Design of an Optimal Fuzzy Controller of an Under-Actuated Manipulator Based on Teaching-Learning-Based Optimization // Acta mechanica et automatica. 2019. vol. 13. no. 3. pp. 166-172.

18. Busson D., Bearee R., Olabi A. Task-oriented rigidity optimization for 7-DOF redundant manipulators // IFAC-PapersOnLine. 2017. vol. 50. no. 1. pp. 14588-14593.

19. Kulakov F., Kadry S., Alferov G., Sharlay A. Bilateral Remote Control over Space Manipulators // AIP Conference Proceedings. 2018. vol. 2040. no. 1. pp. 150015.

20. Cen L., Melkote S.N. Effect of Robot Dynamics on the Machining Forces in RoboticMilling // Procedia Manufacturing. 2017. vol. 10. pp. 486-496.

21. Архипов В.В., Наумов В.Б. Искусственный интеллект и автономные устройства в контексте права: о разработке первого в России закона о робототехнике // Труды СПИИРАН. 2017. ВЫп. 6(55). С. 46-62.

22. Di Vito D., Natale C., Antonelli G. A Comparison of Damped Least Squares Algorithms for Inverse Kinematics of Robot Manipulators // IFAC-PapersOnLine. 2017. vol. 50. no. 1. pp. 6869-6874.

23. Faria $C$. et al. Position-based kinematics for 7-DoF serial manipulators with global configuration control, joint limit and singularity avoidance // Mechanism and Machine Theory. 2018. vol. 121. pp. 317-334.

24. Kumar P.B., Verma N.K., Parhi D.R., Priyadarshi D. Design and control of a 7 DOF redundant manipulator arm // Australian Journal of Mechanical Engineering. 2019. vol. 73. pp. 1-12.

25. Me M.N.A., Veladri K. Modeling and Simulation of 7-dof Robotic Manipulator // National Conf. on Technological Advancements in Mechanical Engineering. 2016. pp. 303-309.

26. Faria C. et al. Review of Robotic Technology for Stereotactic Neurosurgery // IEEE Reviews in Biomedical Engineering. 2015. vol. 8. pp. 125-137. 
27. Sutyasadi P., Parnichkun M. Gait Tracking Control of Quadruped Robot Using Differential Evolution Based Structure Specified Mixed Sensitivity Robust Control // Journal of Control Science and Engineering. 2016. vol. 2016. pp. 1-17.

28. Kobayashi T. et al. Adaptive speed controller using swing leg motion for 3-D limitcyclebased bipedal gait // Nonlinear Dynamics. 2016. vol. 84. no. 4. pp. 2285-2304.

29. Garbi G.P. Multivalued Adaptive Neuro-Fuzzy Controller for Robot Vehicle // International Conference on Intelligent Systems and Knowledge Engineering. 2007.

30. Singh M.K, Parhi D.R, Pothal J.K. ANFIS Approach for Navigation of Mobile Robots // 2009 International Conference on Advances in Recent Technologies in Communication and Computing. 2009. pp.727-731.

31. Shieh M.Y. et al. ANFIS based Controller Design for Biped Robots // 2007 IEEE Proceedings of International Conference on Mechatronics. 2007. pp. 1-6.

32. Xia K. et al. Virtual Decomposition Based Modeling for Multi-DOF Manipulator With Flexible Joint // IEEE Access. 2019. vol. 7. pp. 91582-91592.

33. Silawatchananai C., Parnichkun M. Haptics control of an arm exoskeleton for virtual reality using PSO-based fixed structure $\mathrm{H} 1$ control // International Journal of Advanced Robotic Systems. 2019. vol. 16. no. 3. pp. 1-15.

34. Al Mashhadany Y., Gaeid K.S., Awsaj M.K. Intelligent Controller for 7-DOF Manipulator Based upon Virtual Reality Model // 2019 12th International Conference on Developments in eSystems Engineering (DeSE). 2019. pp. 687-692.

35. Budiharto $W$., Jazidie A., Purwanto D. Indoor Navigation using Adaptive Neuro Fuzzy Controller for Servant Robot // 2010 Second International Conference on Computer Engineering and Applications. 2010. vol. 1. pp. 582-586.

36. Luecke G.R. Haptic Interactions Using Virtual Manipulator Coupling with Applications to Underactuated Systems // IEEE transactions on robotics. 2011. vol. 27. no. 4. pp. 730-740.

37. Malafeyev $O$., Alferov G., Andreyeva $M$. Group strategy of robots in game-theoretic model of interception with incomplete information // 2015 International Conference on Mechanics-Seventh Polyakhov's Reading. 2015. pp. 1-3.

38. Muslim M.A., Rusli M., Zufaryansyah A.R., Ibrahim B.S.K.K. Development of a quadruped mobile robot and its movement system using geometric-based inverse kinematics // Bulletin of Electrical Engineering and Informatics. 2019. vol. 8. no. 4. pp. 1224-1231.

39. Lin N.I., Lee C.S. Measurement of the Robot Motor Capability of a Robot Motor System: A Fitts's-Law-Inspired Approach // Sensors. 2013. vol. 13(7). pp. 8412-8430.

40. Al-Mashhadany. Y.I. Modeling and Simulation of Adaptive Neuro-Fuzzy Controller for Chopper-Fed DC Motor Drive // 2011 IEEE Applied Power Electronics Colloquium (IAPEC). 2011. pp. 110-115.

41. Lopez-Franco C. et al. Inverse kinematics of mobile manipulators based on differential evolution // Int. Journal of Advanced Robotic Systems. 2018. vol. 15. no. 1. pp. 1-22.

42. Alferov G.V., Malafeyev O.A., Maltseva A.S. Game-theoretic model of inspection by anticorruption group // AIP Conference Proceedings. 2015. vol. 1648. no. 1. pp. 450009.

43. Hussien A.A. et al. DTC Controller Variable Speed Drive of Induction Motor with Signal Processing Technique // 2019 12th International Conference on Developments in eSystems Engineering (DeSE). 2019. pp. 681-686.

44. Ivanov G., Alferov G., Sharlay A., Efimova P. Conditions of Asymptotic Stability for Linear Homogeneous Switched System // AIP Conference Proceedings. 2017. vol. 1863. no. 1. pp. 080002. 